\title{
Forskolin promotes astroglial differentiation of human central neurocytoma cells
}

\author{
Bum Jun Kim ${ }^{1}$, Sung Soo Kim ${ }^{1}$ \\ Young Im Kim ${ }^{2}$, Sun $\mathrm{Ha} \mathrm{Paek}$ \\ Young Don Lee $e^{1,3}$ and Haeyoung Suh-Kim ${ }^{1,3,4}$ \\ ${ }^{1}$ Department of Anatomy \\ School of Medicine \\ Ajou University, Suwon 442-749, Korea \\ ${ }^{2}$ Department of Neurosurgery \\ Seoul National University College of Medicine \\ Seoul 110-749, Korea \\ ${ }^{3}$ Brain Disease Research Center \\ School of Medicine \\ Ajou University, Suwon 442-749, Korea \\ ${ }^{4}$ Corresponding author: Tel, 82-31-219-5033; \\ Fax, 82-31-219-5039; E-mail, hysuh@ajou.ac.kr
}

Accepted 23 December 2003

Abbreviations: bFGF, basic fibroblast growth factor; GFAP, glial fibrillary acidic protein; NSE, neuron specific enolase; SNP, synaptophysin

\begin{abstract}
Human central neurocytoma is a kind of the brain tumors that are usually found in anterior part of the lateral ventricles. In this study, we established conditions that allowed proliferation of neurocytoma cells culture and analyzed characteristics of neurocytoma cells in vitro. For in vitro, a condition that used for culturing neural stem cells and contained basic fibroblast growth factor (bFGF) provided high proliferation. RT-PCR analaysis showed that nestin was found in neurocytoma cells, indicating that the neurocytomas possess neural stem cell properties. Interestingly, treatment of neurocytoma cells with forskolin increased expression of glial fibrillary acidic protein with a concomitant decrease in the nestin expression. Forskolin also induced morphological changes of neurocytoma cells to adopt an astrocyte-like phenotype. The results suggest that neurocyotma cells may have properties of multipotent neural stem cells.
\end{abstract}

Keywords: astrocyte; central neurocytoma; forskolin; neural stem cell, neuron; protein kinase $A$

\section{Introduction}

Human central neurocyotoma was first described as one of the benign tumors usually found in the anterior region of lateral ventricles in the brain (Hassoun et al., 1982). Central neurocytomas are composed of uniform round shaped cells with central nuclei and a perinuclear halo (Hassoun et al., 1993). For a long time, neurocytomas were originally believed to be a kind of oligodendroglioma or ependymal glioma due to morphological resemblances to oligodendrocytes and ependymal cells (Hassoun et al., 1982). However, recent reports have shown that neurocytomas are genetically different from oligodendrogliomas and neuroblastomas (Tong et al., 2000).

Several histological studies found expression of neuron-specific enolase (NSE) (Von Deimling et al., 1990; Kubota et al., 1991; Kim et al., 1992) and synaptophysin (Von Deimling et al., 1990; Kim et al., 1992; Ishiuchi and Tamura, 1997) in neurocytomas freshly isolated from the patients. Thus, it is widely accepted that neurocytomas have neuronal characteristics. Interestingly, glial fibrillary acidic protein (GFAP) has been also found in neurocytomas (Von Deimling et al., 1990, 1991; Ishiuchi and Tamura, 1997). The GFAP expression was originally believed to be due to reactive astrocytes located in freshly isolated neurocytomas (Kubota et al., 1991; Figarella- Branger et al., 1992) as well as in cultured neurocytoma cells (Westphal et al., 1994; Westphal et al., 1998). Thus, it remains to be determined whether the cells in neurocytomas have a potential to differentiate into both neurons and astrocytes, or neurocytomas are mixtures of neurons and glial cells.

In this study, we investigated proliferation properties and the expression level of nestin, a well known neural stem cell marker in neurocytomas to determine the multipotency of neurocytoma cells isolated from Korean patients. We found that the activation of protein kinase A (PKA) signaling pathway with forskolin induces astroglial differentiation of neurocytoma cells.

\section{Materials and Methods}

Cell culture

Human central neurocytoma were diagnosed as described previously (Paek et al., 2003) and isolated from two Korean patients who underwent craniotomy cell were for lateral ventricle tumors. Cultured in DMEM/ 
F12 (1:1) containing 2\% fetal bovine serum (FBS), 20 $\mathrm{ng} / \mathrm{ml}$ basic fibroblast growth factor (bFGF, Dong-A Pharmaceutical Co., Yongin, Korea) and N2 supplement (GIBCO, BRL, Grand Island, NY) in the atmosphere of $5 \% \quad \mathrm{CO}_{2}$ and $95 \%$ air at $37^{\circ} \mathrm{C}$. Medium was changed twice a week. Hepatocyte growth factor (HGF, a kind gift from Dr. JH Lee, Ajou Univ., Korea) was added to the culture to a final concentration of $10 \mathrm{ng} / \mathrm{ml}$ instead of $\mathrm{bFGF}$. To determine the effect of PKA, forskolin (Sigma, St. Louis, MO) was added to the cells to a final concentration of $30 \mathrm{mM}$ in DMEM/F12 (1:1) containing $0.5 \%$ FBS and N2 supplement.

\section{RT-PCR}

Total RNA was prepared from cells after differentiation using RNAZol-B solution (Tel-Test Inc., Friendswood, TX) according to the recommendations of manufacturer. Superscript kit (Invitrogen, Rockville, MD) was used for cDNA synthesis. The PCR reactions were carried out according to standard protocols. Primer sequences (forward and backward) and product sizes (base pairs) were as follows: human nestin (5' GGCAGCGTTGGAACAGAGGTTGGA 3', 5' CTCTAAACTGGAGTGGTCAGGGCT 3', 718 bp), human GFAP(5' GAGTCGCTGGAGGAGGAGATC 3', 5' GGGACTCGTTCGTGCCGCGC 3', 345 bp), human NSE (5' AAGGACAAATACGGCAAGGA 3', 5' TGGAC CAGGCAGCCCAATC 3', 328 bp), human NF-L (5' TCCTACTACACCATCCATGT 3', 5' TCCCCAGCACC TTCAACTTT 3', 285 bp) and human GAPDH (5' CC ACAGTCCATGCCATCACT 3', GAGCTTGACAAAGT GGTCGT 3', 403 bp).

\section{Immunocytochemistry}

After treatment of forskolin for 1 week, neurocytoma cells were fixed with PBS containing $4 \%$ paraformaldehyde. The fixed cells were incubated with $5 \%$ normal horse serum followed by incubation with anti-nestin antibody (monoclonal, 1:100, Chemicon, Temecula, CA), anti-GFAP antibody (monoclonal, 1:200, Sigma, St. Louis, MO) or anti-b-tubulin III antibody (monoclonal, 1:500, Babco, Richmond, CA) overnight at $4^{\circ} \mathrm{C}$. After sufficient washing with PBS containing $0.01 \%$ triton X-100, cells were incubated with FITC conjugated anti-mouse IgG (1:200, Vector, Burlingame, CA) for one hour at room temperature. Immunoreactivity was detected with a fluorescence microscope.

\section{Results}

\section{Central neurocytoma cells express nestin}

Dissociated cells from neurocytoma cells were origi- nally plated on DMEM/F12 (1:1) containing 2\% FBS and subsequently kept in the presence of $b F G F$ and N2 supplement. The cells exhibited a round cell body with bipolar or multipolar processes (Figure 1A). It has been previously reported that neurocytoma cells isolated from Japanese patients could be differentiated to neuronal cells and glial cells in vitro (Ishiuchi et al., 1998). To characterize multipotency of neurocytoma cells, the expression level of the nestin gene was determined. Nestin is a class VI intermediate filament proteins and a well-known marker for stem cells in the nervous system (Andressen et al., 2001; Kawaguchi et al., 2001). Total RNA was isolated from neurocytoma cells grown in the presence of bFGF and carried out RT-PCR. The primers were designed to span the exons 1 and 2 of the nestin gene to eliminate contamination of genomic DNA. The nestin cDNA was amplified as a $718 \mathrm{bp}$, indicating that neurocytoma cells contain neural stem cells (Figure 1B).

A
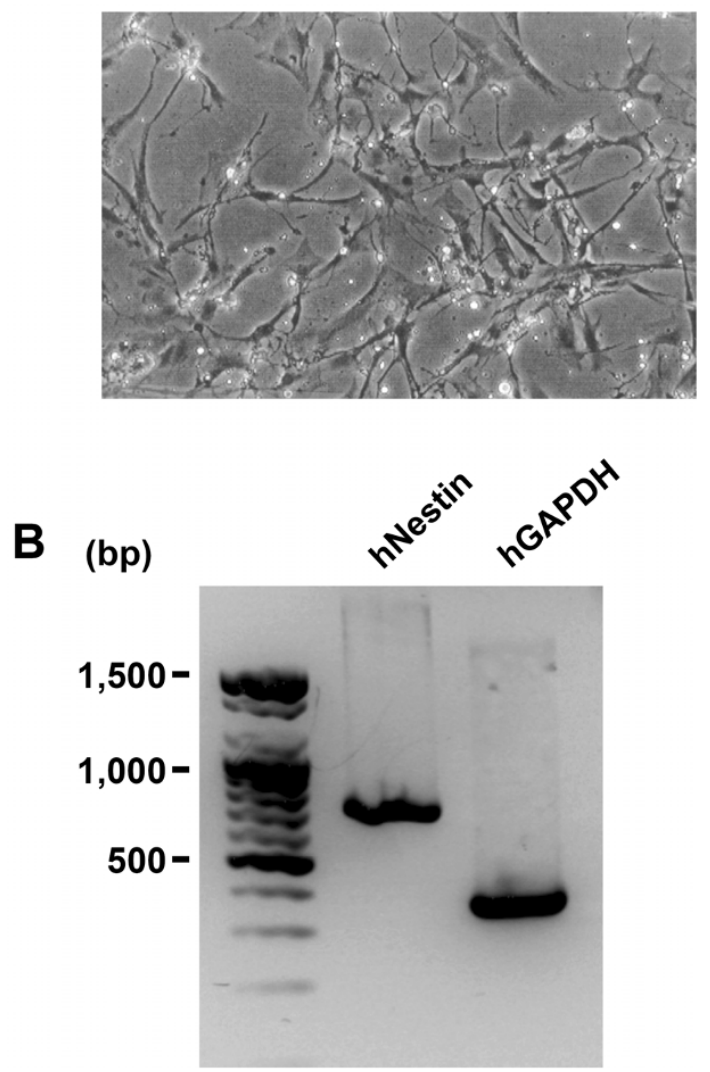

Figure 1. Characterization of central neurocytoma cells. (A) The cells exhibited a round cell body with bipolar or multipolar processes in DMEM/F12 (1:1) containing 2\% FBS, $20 \mathrm{ng} / \mathrm{ml}$ bFGF and N2 supplement. (B) RT-PCR with primers for human specific nestin (hNestin) or human GAPDH (hGAPDH) yielded PCR products of nestin (718 bp) and GAPDH (403 bp), respectively. 


\section{Neurocytomas proliferate in response to bFGF}

Neural stem cells can form neurospheres in the presence of bFGF in serum free media (Chiasson et al., 1999; Ciccolini et al., 2001). However, we were unable to obtain neurospheres from neurocytoma cells in the presence of $b F G F$ in serum free medium. Instead, $20 \mathrm{ng} / \mathrm{ml} \mathrm{bFGF}$ facilitated proliferation of neurocytoma cells in DMEM/F12 (1:1) containing 2\% FBS and N2 (Figure 2). Also, HGF known to facilitate regeneration of damaged tissues (Matsumoto and Nakamura, 1997; Ohmichi et al., 1998) increased growth of neurocytoma cells (Figure 2). The data suggest that neurocytoma cells are similar to neural stem cells in terms of responsiveness to bFGF.

\section{The effect of forskolin on differentiation of neurocytoma cells}

Activation of cAMP dependent protein kinase A (PKA) has been known to cause various effects on differentiation in neural precursor cells. To determine the effect of PKA, forskolin was added to a final concentration of $30 \mathrm{mM}$ to neurocytoma cells for a week. Before treatment of forskolin, neurocytoma cells exhibited a round cell body with bipolar or multipolar processes (Figure 3A). Treatment of forskolin induced morphological changes so that the cells outgrew processes (Figure 3A). To determine whether morphological changes accompanied expression of specific markers for astrocytes or neurons, total RNA was isolated from neurocytoma cells before and after treatment of forskolin and RT-PCR was carried out for the presence of nestin, GFAP, neurofilament-L (NF-L) and NSE. Interestingly, the expression level of GFAP was increased by forskolin, whereas expression of the nestin and NF-L genes was decreased (Figure 3B), indicating that neurocytoma cells lost neural stem cell properties and adopted an astrocyte fate. During the procedure, the expression level of NSE was not significantly altered. To confirm induction of astroglial differentiation of neurocytoma by forskolin, immunocytochemistry was carried out with antibodies against nestin, GFAP, and b-tubulin III (Figure 4). Forskolin reduced the number of nestin-positive cells but increased the GFAP-positive cells. In contrast, the number of b-tubulin III positive cells was not significantly altered by the forskolin treatment. The consistent data obtained by RT-PCR analysis and immunocytochemistry suggest that neurocytoma cells can differentiate into astrocytes by the treatment of forskolin.

\section{Discussion}

In this study, neurocytoma cells were shown to proliferate in response to bFGF and express the nestin

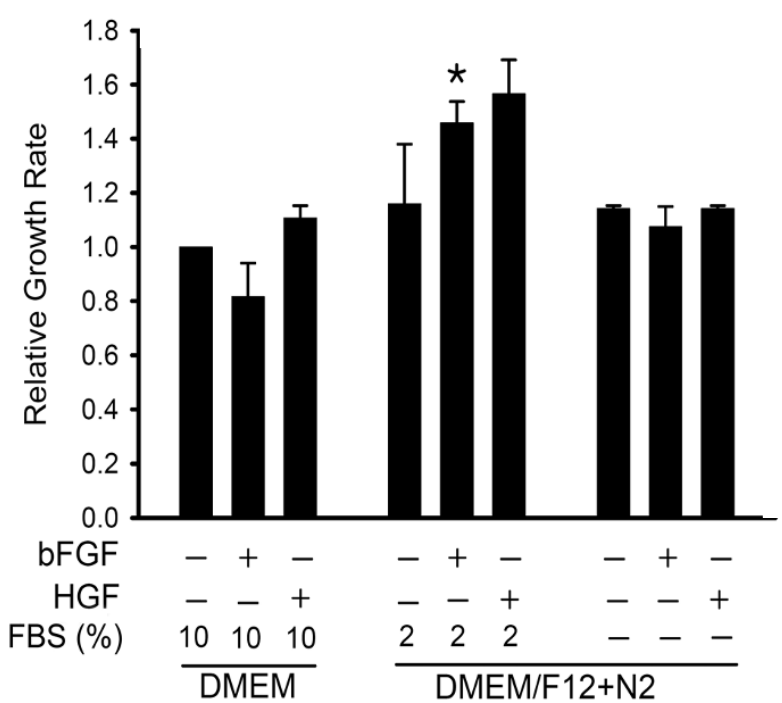

Figure 2. The effect of bFGF. Central neurocytoma cells highly proliferated in response to $20 \mathrm{ng} / \mathrm{ml}$ bFGF or HGF in DMEM/F12 (1:1) containing $2 \% \mathrm{FBS}$ and $\mathrm{N} 2$ supplement. Data are shown as the averages $\pm S E M$ from three independent experiments. Statistical significance was determined by Student's t-test: ${ }^{*} P<0.05$.

A

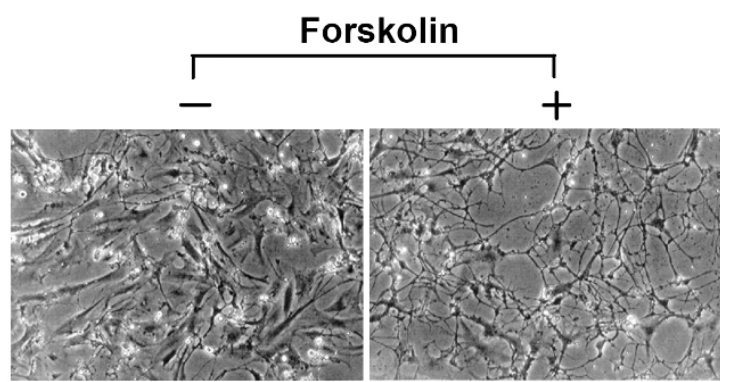

B

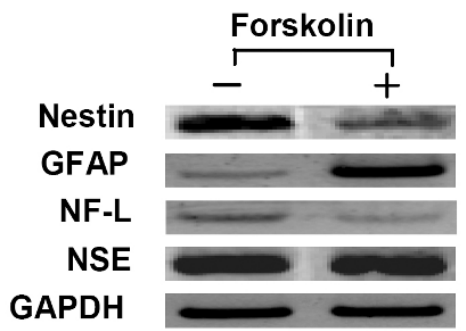

Figure 3. The effect of forskolin. Central neurocytoma cells were grown in the presence of $30 \mathrm{mM}$ forskolin for 1 week. Forskolin induced morphological changes of central neurocytoma cells (A) and increased expression of GFAP (B). RT-PCR showed that GFAP was up-regulated and the expression of nestin and NF-L was downregulated.

gene in the proliferating condition with a minimum expression of NF-L and GFAP. Treatment of forskolin was found to increase expression of GFAP, an astrocyte marker with a concomitant decrease in expression of nestin and NF-L. 


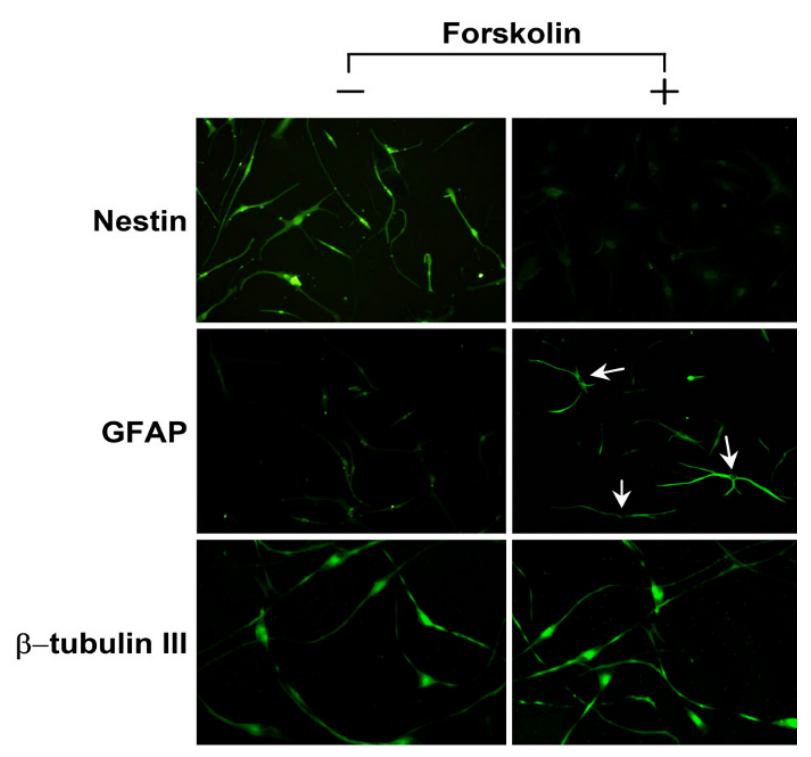

Figure 4. Immunocytochemistry before and after forskolin treatment. Central neurocytoma cells were grown in the presence of $30 \mathrm{mM}$ forskolin for 1 week. The cells were fixed and stained with anti-nestin, anti-GFAP, and anti-b-tubulin III antibodies. Immunoreactivity was visualized with a FITC-conjugated anti-mouse $\lg \mathrm{G}$.

Neural stem cells are categorized by self-renewing ability in response to bFGF and expression of the nestin gene (Tropepe et al., 1999). The neurocytoma cells isolated from Korean patients highly proliferate in the presence of bFGF (Figure 2) and express the nestin gene. These data indicate that neurocytoma cells may have properties of neural progenitors or neural stem cells. Importantly, the nestin expression decreases when the cells undergo glial differentiation after treatment of forskolin (Figure 3B). It should be however, also noted that in the presence of bFGF, neurocytoma cells cannot form neurospheres in the serum free condition, which is the hallmark of neural stem cells (data not shown).

Activation of the PKA signaling pathway has phenotypic effects on differentiation of neural precursor cells. In this study, forskolin increases GFAP expression in neurocytoma cells while repressing expression of NF-L (Figure 3B). Increment of GFAP expression was also confirmed by immunocytochemistry at the expense of nestin (Figure 4). Neurocytoma cells already express b-tubulin III, an early neuronal marker (Svendsen et al., 2001), and treatment with forskolin does not further increase it. Thus, the effect of forskolin is specific to astroglial differentiation.

PKA signaling pathway evoked by forskolin or cAMP can play a key role in differentiation of neural precursor cells. In neuroblastoma cells, forskolin or cell permeable analogues of CAMP cause neuronal differentiation including neurite outgrowth and expression of neuron specific genes (Bouron et al., 1999;
Ghil et al., 2000; De Jonge et al., 2001; Kim et al., 2002). On the contrary, cAMP increases glial differentiation in primary cultures of cells isolated from developing rat cortex (McManus et al., 1999; Grimaldi, 1999). Although astroglial differentiation of neurocytoma cells has been previously reported after longterm culture (Westphal et al., 1994; Ishiuchi et al., 1998; Westphal et al., 1998), the effect of forskolin was first demonstrated in neurocytoma cells in this study.

In summary, we demonstrated that neurocytoma cells isolated from Korean patients have self-renewing properties in response to bFGF similar to nestinpositive neural stem cells and activation of PKA pathway induce the cells to adopt an astrocyte cell fate. Thus, studies with neurocytoma may provide a useful tool to study how genetic and epigenetic program regulates neuronal and glial differentiation in human progenitor cells and to understand how abnormal regulation of proliferation leads to tumor.

\section{Acknowledgement}

This research was supported by grants MI-0108-000083 from Neurobiology Research Program and M103KV010010-03K2201-01010 from Brain Research Center of the 21st Century Frontier Research Program funded by the Ministry of Science and Technology of Republic of Korea; and by KOSEF through Brain Disease Research Center at Ajou University.

\section{References}

Andressen C, Stocker E, Klinz FJ, Lenka N, Hescheler J, Fleishmann B, Arnhold S, Addicks K. Nestin-sepcific green fluorescent protein expression in embryonic stem cell-derived neural progenitor cells used for transplantation. Stem Cells 2001;19:419-24

Bouron A, Becker C, Prozig H. Functional expression of voltage-gated $\mathrm{Na}^{+}$and $\mathrm{Ca}^{2+}$ channels during neuronal differentiation of PC12 cells with nerve growth factor or forskolin. Naunyn Schmiedebergs Ach Pharmacol 1999;359:370-7

Chiasson BJ, Tropepe V, Morshead CM, van der Kooy D. Adult mammalian forebrain ependymal and subependymal cells demonstrate proliferative potential, but only subependymal cells have neural stem cell characteristics. J Neurosci 1999;19:4462-71

Ciccolini F. Identification of two distinct types of multipotent neural precursors that appear sequentially during CNS development. Mol Cell Neurosci 2001;17:895-907

De Jonge RR, Van Schaik IN, Vermeulen M, Kwa MS, Baas $F$. CAMP is involved in the differentiation of human teratocarcinoma cells. Neurosci Lett 2001;311:61-5

Figarella-Branger D, Pllessier JF, Dauma-Duport C, Delisle MB, Pasquier B, Parent M, Gambarelli D, Rougon G, Has- 
soun J. Central neurocytomas: critical evaluation of a smallcell neuronal tumour. American J Surg Pathol 1992;16:97-109

Ghil SH, Kim BJ, Lee YD, Suh-Kim H. Neurite outgrowth induced by cyclic AMP can be modulated by the subunit of Go. J Neurochem 2000;74:151-8

Goldman JE, Chiu FC. Dibutyryl cyclic AMP causes intermediate filament accumulation and actin reorganization in astrocytes. Brain Res 1984;306:85-95

Grimaldi M, Favit A, Alkon DL. CAMP-induced cytoskeleton rearrangement increases calcium transients through the enhancement of capacitative calcium entry. J Biol Chem 1999; 274:33557-64

Hassoun J, Gambarelli D, Grisoli F, Pellet W, Salamon G, Pellissier JF, Toga M. Central neurocytoma. An electronmicroscopic study of two cases. Acta Neuropathol (Berl) 1982;56:151-6

Hassoun J, Soylemezolu F, Gamberelli D, Figarella-Branger $D$, von Ammon K, Kleihues P. Central neurocytoma: a synopsis of clinical and histological features. Brain Pathol 1993; 3:297-306

Ishiuchi S, Tamura M. Central neurocytoma: an immunohistochemical, ultrastructural and cell culture study. Acta Neuropathol 1997;94:425-35

Ishiuchi S, Nakazato Y, lino M, Ozawa S, Tamura M, Ohye C. In vitro neuronal and glial production and differentiation of human central neurocytoma cells. J Neurosci Res 1998; 51:526-35

Kawaguchi A, Miyata T, Sawamoto K, Takachita H, Murayama A, Akamatsu W, Ogawa M, Okabe M, Tano Y, Goldman SA, Okano $H$ Nestin-EGFP transgenic mice: visualization of the self-renewal and multipotency of CNS stem cells. Mol Cell Neurosci 2001;17:259-73

Kim DG, Chi JG, Park SH, Chang KH, Lee SH, Jung HW, Kim HJ, Cho BK, Choi KS, Han DH. Intraventricular neurocytoma: clinicophathologicla analysis of seven cases. J Neurosurg 1992;76:759-65

Kim G, Choe Y, Park J, Cho S, Kim K. Activation of protein kinase A induces neuronal differentiation of HiB5 hippocampal progenitor cells. Mol Brain Res 2002;109:134-45

Kubota T, Hayashi M, Kawano $H$, Sato K, Ishise J, Kawamoto K, Shirataki K, lizuka H, Tsunoda S, Katsuyama J. Central neurocytoma: immunohistochemical and ultrastructural study. Acta Neuropathol 1991;81:418-27
Matsumoto K, Nakamura T. Hepatocyte growth factor (HGF) as a tissue organizer for organogenesis and regeneration. Biochem Biophys Res Commun 1997;239:639-44

McManus MF, Chen LC, Vallejo I, Vallejo M. Astroglial differentiation of cortical precursor cells triggered by activation of the cAMP-dependent signaling pathway. J Neurosci 1999; 19:9004-15

Ohmichi H, Koshimizu U, Matsumoto K, Nakamura T. Hepatocyte growth factor (HGF) acts as a mesenchyme-derived morphogenic factor during fetal lung development. Development 1998;125:1315-24

Paek SH, Kim JE, Kim DG, Han MH, Jung HW. Angiographic characteristics of central neurocytoma suggest the origin of tumor. J Korean Med Sci 2003;18:573-80

Svendsen CN, Bhattacharyya A, Tai YT. Neurons from stem cells: preventing an identity crisis. Nat Rev Neurosci. 2001; 2:831-4

Tong CYK, Ng HK, Pang JCS, Hu J, Hui ABY, Poon WS. Central neurocytomas are genetically distinct from oligodendrogliomas and neuroblastomas. Histopathol 2000;37:160-5

Tropepe V, Sibilia M, Ciruna BG, Rossant J, Wagner EF, van der Kooy $D$. Distinct neural stem cells proliferate in response to EGF and FGF in the developing mouse telencephalon. Dev Biol 1999;208:166-88

Tsuchida T, Matsumoto M, Shirayame $\mathrm{Y}$, Imahori T, Kasai $\mathrm{H}$, Kawamoto K. Neuronal and glial characteristics of central neurocytoma: electron microscopical analysis of two cases. Acta Neuropathol 1996;91:573-7

Von Deimling $A$, Janzer $R$, Keihues $P$, Wiestler OD. Patterns of differentiation in central neurocytoma: an immunohistochemical study of eleven biopsies. Acta Neuropathol 1990; 79:473-9

Von Deimling A, Kleihues $P$, Saremaslani $P$, Yasargil GM, Spoerri $O$, Sudhof TC, Weistler OD. Histogenesis and differentiation potential of central neurocytomas. Lab Inves 1991; 64:585-91

Westphal M, Stavrou D, Nausch H, Valdueza JM, Herrmann HD. Human neurocytoma cells in culture show characteristics of astroglial differentiation. J Neurosci Res 1994;38:698-704

Westphal M, Meissner H, Matschke J, Herrmann HD. Tissue culture of human neurocytomas induces the expression of glial fibrilary acidic protein. J Neurocytol 1998;27:805-16 